\title{
ANALYZING OF CUSTOMER REQUIREMENTS TO ERIC MOBILE APPLICATION
}

\author{
Abstract. Users in transport, forwarding and logistics companies use the mobile technologies for connect to existing \\ information systems. By solving the ERIC Mobile project, these services will also be available on mobile devices. \\ The article is aimed at lancing the requirements of all types of customers for the ERIC Mobile app. After the basic \\ characteristics of the mobile device, the operation systems, the application development typology, the authors focus \\ on the developing application "ERIC Mobile". The aim of the article is to provide relevant requirements for further \\ research and development of the software application of the rail freight information centre in Europe for end users of \\ mobile devices such as smartphones and tablets. \\ Keywords: applications for mobile devices, transportation a forwards companies, ERIC Mobile, \\ Juraj Čamaj ${ }^{1}$ \\ ${ }^{1}$ Faculty of Operation and Economics of Transport and Communications, University of Žilina, \\ Univerzitná 8215/1, 01026 Žilina, Slovakia.+42141513 3423; juraj.camaj@fpedas.uniza.sk \\ Jaroslav Mašek ${ }^{2}$ \\ ${ }^{2}$ Faculty of Operation and Economics of Transport and Communications, University of Žilina, \\ Univerzitná 8215/1, 01026 Žilina, Slovakia. +42141513 3423; jaroslav.masek@fpedas.uniza.sk \\ Martin Kendra ${ }^{3}$ \\ ${ }^{3}$ Faculty of Operation and Economics of Transport and Communications, University of Žilina, \\ Univerzitná 8215/1,01026 Žilina, Slovakia.+42141513 3429; martin.kendra@fpedas.uniza.sk
}

\section{Introduction}

The purpose of using a mobile phone is no longer as limited as a few years ago. Today's devices no longer have the slightest problem with full browsing, navigation, or video recording. Their success stems from the simplicity of processing, the sleek design, the modern technologies, but a significant part of the success is also attributed to the operating system.

The article addresses customer requirements for the developing ERIC Mobile application. After the general definition of mobile devices and their general user features, the authors focus on the creating ERIC Mobile application. The requirements for this app come from an existing ERIC desktop application. Preferences vary depending on the diversity of subjects in the transport market and their preferences.

\section{Mobile Devices}

A mobile device (or handheld computer) is a computing device small enough to hold and operate in the hand. Typically, any handheld computer device will have an LCD flat screen interface, providing a touchscreen interface with digital buttons and keyboard or physical buttons along with a physical keyboard. Many such devices can connect to the Internet and interconnect with other devices such as car entertainment systems or headsets via Wi-Fi, Bluetooth, cellular networks or near field communication (NFC). Integrated cameras, digital media players, the ability to place and receive telephone calls, video games, and Global Positioning System (GPS) capabilities are common (Tengler - Abramović Achimský, 2018). Power is typically provided by a lithium battery. Mobile devices may run mobile operating systems that allow third-party apps specialized for said capabilities to be installed and run.
Early smartphones were joined in the late 2000s by larger, but otherwise essentially the same, tablets. Input and output is now usually via a touch-screen interface. Phones/tablets and personal digital assistants may provide much of the functionality of a laptop/desktop computer but more conveniently, in addition to exclusive features. Enterprise digital assistants can provide additional business functionality such as integrated data capture via barcode, RFID and smart card readers. By 2010, mobile devices often contained sensors such as accelerometers, magnetometers and gyroscopes, allowing detection of orientation and motion. Mobile devices may provide biometric user authentication such as face recognition or fingerprint recognition (Ihnát - Gašparík, 2008).

There are many kinds of mobile devices, designed for different applications (Čamaj - Gašparík, 2011). These include:

- mobile Internet devices;

- tablets/Smartphones;

- laptops;

- wearable computers;

- calculator watches;

- smartwatches;

- head-mounted displays;

- personal digital assistants;

- enterprise digital assistants;

- ultra-mobile PCs;

- etc...

\section{Mobile Operating System}

An operating system (OS) is system software that manages computer hardware and software resources and provides common services for computer programs. 
Time-sharing operating systems schedule tasks for efficient use of the system and may also include accounting software for cost allocation of processor time, mass storage, printing, and other resources. (Čamaj, 2018)

A mobile operating system (or mobile OS) is an operating system for phones, tablets, smartwatches, or other mobile devices. While computers such as typical laptops are 'mobile', the operating systems usually used on them are not considered mobile ones, as they were originally designed for desktop computers that historically did not have or need specific mobile features. This distinction is becoming blurred in some newer operating systems that are hybrids made for both uses.

Mobile operating systems combine features of a personal computer operating system with other features useful for mobile or handheld use; usually including, and most of the following considered essential in modern mobile systems; a wireless inbuilt modem and SIM tray for telephony and data connection, a touchscreen, cellular, Bluetooth, Wi-Fi Protected Access, Wi-Fi, Global Positioning System (GPS) mobile navigation, video- and single-frame picture cameras, speech recognition, voice recorder, music player, near field communication, and infrared blaster. Android alone is more popular than the popular desktop operating system Windows, and in general smartphone use (even without tablets) outnumber desktop use. (Tengler - Kolarovszki Kolarovszka, 2017)

Mobile devices with mobile communications abilities (e.g., smartphones) contain two mobile operating systems - the main user-facing software platform is supplemented by a second low-level proprietary real-time operating system which operates the radio and other hardware. Research has shown that these low-level systems may contain a range of security vulnerabilities permitting malicious base stations to gain high levels of control over the mobile device.

Mobile operating systems have majority use since 2017 (measured by web use); with even only the smartphones running them (excluding tablets) more used than any other kind of device. Thus traditional desktop OS is now a minority used kind of OS; see usage share of operating systems. (Tengler - Abramović - Achimský, 2018

As the most popular mobile OS we can selected:

- Android.

- iPhone OS;

- Windows Phone;

- Symbian;

- BlackBerry.

The following graph show the shares of the phone operating systems in the period 05/2017-04/2018.

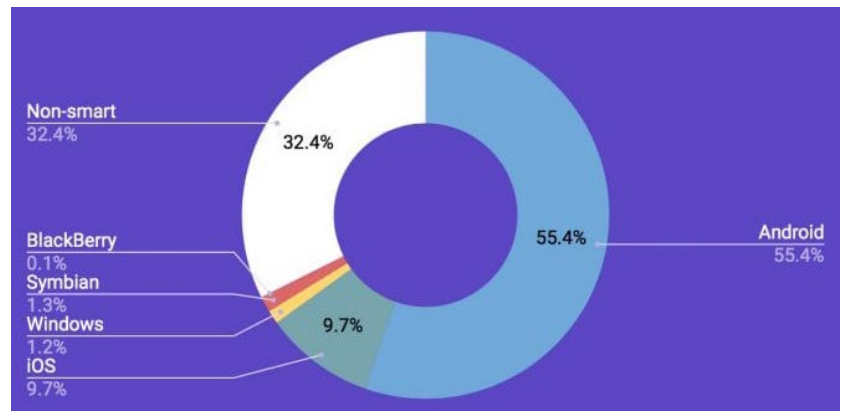

Fig. 1. The shares of the phones operating systems

Source: Menšík, 2018

\subsection{Operational system Android}

Android is a mobile operating system developed by Google. It is based on a modified version of the Linux kernel and other open source software, and is designed primarily for touchscreen mobile devices such as smartphones and tablets. (Tengler - Kolarovszki Kolarovszka, 2017)

Android is also associated with a suite of proprietary software developed by Google, called Google Mobile Services (GMS) that very frequently comes pre-installed in devices, which usually includes the Google Chrome web browser and Google Search and always includes core apps for services such as Gmail, as well as the application store and digital distribution platform Google Play, and associated development platform. These apps are licensed by manufacturers of Android devices certified under standards imposed by Google, but AOSP has been used as the basis of competing Android ecosystems, such as Amazon.com's Fire OS, which use their own equivalents to GMS. (Android - operating system, 2018)

Android has been the best-selling OS worldwide on smartphones since 2011 and on tablets since 2013. As of May 2017, it has over two billion monthly active users, the largest installed base of any operating system, and as of June 2018, the Google Play store features over 3.3 million apps. (Android - operating system, 2018)

The Android platform itself provides not only an end-user operating system but also a complete operating system deployment solution (driver specification, etc.) for mobile operators and device manufacturers, and, last but not least, for application developers, provides effective tools for their development - Software Development Kit.(Tengler - Kolarovszki - Fabuš - Fabušová, 2018)

Android is divided into 5 layers where each layer has its purpose and need not be separated from the other layers. They are:

- the core;

- libraries;

- Android Runtime layer;

- application framework layer;

- the Layer of elementary applications. 


\section{$3.2 \mathrm{iOS}$}

iOS (formerly iPhone OS) is a mobile operating system created and developed by Apple Inc. exclusively for its hardware. It is the operating system that presently powers many of the company's mobile devices, including the iPhone, iPad, and iPod Touch. (Tengler - Kolarovszki - Kolarovszka, 2017) It is the second most popular mobile operating system globally after Android.

Originally unveiled in 2007 for the iPhone, iOS has been extended to support other Apple devices such as the iPod Touch (September 2007) and the iPad (January 2010). As of March 2018, Apple's App Store contains more than 2.1 million iOS applications. (iPhone OS, 2018)

The iOS user interface is based upon direct manipulation, using multi-touch gestures. Interface control elements consist of sliders, switches, and buttons. Interaction with the OS includes gestures such as swipe, tap, pinch, and reverse pinch, all of which have specific definitions within the context of the iOS operating system and its multi-touch interface. Internal accelerometers are used by some applications to respond to shaking the device (one common result is the undo command) or rotating it in three dimensions (one common result is switching between portrait and landscape mode). Apple has been significantly praised for incorporating thorough accessibility functions into iOS, enabling users with vision and hearing disabilities to properly use its products. (iPhone OS, 2018)

Major versions of iOS are released annually. On all recent iOS devices, iOS regularly checks on the availability of an update, and if one is available, will prompt the user to permit its automatic installation. iOS is composed of the following four layers:

- Core OS (system core);

- Core Services (Basic Services);

- Media layer;

- Cocoa Touch layer (user interface or GUI and its API).

\subsection{Operational system Windows Phone}

Windows Phone (WP) is a family of discontinued mobile operating systems developed by Microsoft for smartphones as the replacement successor to Windows Mobile and Zune. Windows Phone features a new user interface derived from Metro design language. Unlike Windows Mobile, it is primarily aimed at the consumer market rather than the enterprise market. It was first launched in October 2010 with Windows Phone 7. Windows Phone 8.1 is the latest public release of the operating system, released to manufacturing on April, 2014. (Windows Phone, 2018)

Windows Phone was succeeded by Windows 10 Mobile in 2015; it emphasizes a larger amount of integration and unification with its PC counterpartincluding a new, unified application ecosystem, along with an expansion of its scope to include small-screened tablets.
In January 2019, Microsoft announced that support for Windows 10 Mobile would end on December 10, 2019, and that Windows 10 Mobile users should migrate to iOS or Android phones. (Windows Phone, 2018)

\subsection{Operational system Symbian}

Symbian is a discontinued mobile operating system (OS) and computing platform designed for smartphones. Symbian was originally developed as a closed-source OS for PDAs in 1998 by the Symbian Ltd. consortium. Symbian OS was a descendant of Psion's EPOC, and ran exclusively on ARM processors, although an unreleased x86 port existed. Symbian was used by many major mobile phone brands, like Samsung, Motorola, Sony Ericsson, and above all by Nokia. It was also prevalent in Japan by brands including Fujitsu, Sharp and Mitsubishi. As a pioneer that established the smartphone industry, it was the most popular smartphone OS on a worldwide average until the end of 2010 - at a time when smartphones were in limited use, when it was overtaken by Android, as Google and its partners achieved wide adoption. (Symbian OS, 2018)

The Symbian OS platform was formed of two components: one being the microkernel-based operating system with its associated libraries, and the other being the user interface (as middleware), which provides the graphical shell atop the OS. The most prominent user interface was the S60 (formerly Series 60) platform built by Nokia. Another interface was the $\operatorname{MOAP}(\mathrm{S})$ platform from carrier NTT DoCoMo in the Japanese market. Applications of these different interfaces were not compatible with each other, despite each being built atop Symbian OS. (Symbian OS, 2018)

\subsection{Operational system BlackBerry OS (RIM)}

BlackBerry OS is a proprietary mobile operating system developed by Canadian company BlackBerry Limited for its BlackBerry line of smartphone handheld devices. The operating system provides multitasking and supports specialized input devices that have been adopted by BlackBerry for use in its handhelds, particularly the trackwheel, trackball, and most recently, the trackpad and touchscreen. (BlackBerry OS, 2018)

The BlackBerry platform was perhaps best known for its native support for corporate email, through Java Micro Edition MIDP 1.0 and, more recently, a subset of MIDP 2.0, which allowed complete wireless activation and synchronization with Microsoft Exchange, Lotus Domino, or Novell GroupWise email, calendar, tasks, notes, and contacts, when used with BlackBerry Enterprise Server. The operating system also supported WAP 1.2.

Updates to the operating system may be automatically available from wireless carriers that support the BlackBerry over the air software loading (OTASL) service. (BlackBerry OS, 2018)

Third-party developers can write software using the available BlackBerry API classes, although applications 
that make use of certain functionality must be digitally signed.

\section{The type of applications in mobile devices}

The mobile applications can be selected to tree basic groups:

1. Native apps

2. Hybrid apps

3. Web apps

\subsection{Native apps}

Such apps are developed for a single mobile operating system exclusively; therefore, they are "native" for a particular platform or device. App built for systems like iOS, Android, Windows phone, Symbian, Blackberry can not be used on a platform other than their own. In other words, you won't be able to use Android app on iPhone. (Tengler - Kolarovszki - Kolarovszka, 2017)

Main advantage of native apps is high performance and ensuring good user experience as developers use native device UI. Moreover, an access to wide range of APIs that puts no limitation on app usage. Native applications are distinctly accessible from app stores of their kind and have the clear tendency to reach target customers.

Some cons to native apps are higher cost compared to other types of apps - due to the need of creating app duplicates for other platforms, separate support and maintenance for different types of apps resulting in bigger product price. (Tengler - Kolarovszki - Fabuš Fabušová, 2018)

\subsection{Hybrid apps}

They are build using multi-platform web technologies (for example HTML5, CSS and Javascript). So-called hybrid apps are mainly website applications disguised in a native wrapper. Apps possess usual pros and cons of both native and web mobile applications. (Tengler - Kolarovszki - Kolarovszka, 2017)

Hybrid multi-platform apps are fast and relatively easy to develop - a clear advantage. Single code base for all platforms ensures low-cost maintenance and smooth updates. Widely used APIs, like gyroscope, accelerometer and geolocation are available.

On the other hand, hybrid applications lack in performance, speed and overall optimization in comparison to native apps for instance. Also, there are certain design issues due to app inability to look in exactly same way on two or more platforms. (Tengler Kolarovszki - Fabuš - Fabušová, 2018)

\subsection{Web apps}

These are software applications that behave in a fashion similar to native applications. Web apps use a browser to run and are usually written in HTML5, JavaScript or CSS. These apps redirect a user to URL and offer "install" option by simply creating a bookmark to their page. (Tengler - Kolarovszki - Kolarovszka, 2017)

Web applications require minimum of device memory, as a rule. As all personal databases are saved on a server, users can get access from any device whenever there is internet connection. That is why the use of web apps with poor connection would result in bad user experience. The drawback is access to not that many APIs for developers, with exception of geolocation and few others.

Apps content is only a wrapper on the used device while most of data should be loaded from a server.Performance is inextricably linked due to browser work and network connection. Only up to $14 \%$ of time users spend on mobile websites. And just some of device APIs may be used (such as geolocation) (Tengler Kolarovszki - Fabuš - Fabušová, 2018)

\section{Subjects on transport market and their interaction}

The technological processes of rail transport management are based on the availability of correct and accurate information. In the management of rail transport, it is important to find out how to get the information "at the right time and in the right place"

In the modern area of the liberalized rail transport market, is especially particularly important the criterion of the classification of information systems according to the entity, which expresses the division of competencies, operational responsibility, information and information systems between the infrastructure manager (IM) and the railway undertaking, (RU). (Ihnát - Gašparík, 2008) (Gapšarík - Zitrický, 2010)

In the rail transport market, the railway undertaking offers transport services for the transport of persons and goods, in space and time. On the demand side, the customer is a natural or legal person requesting the relocation of the goods (object of transport) to the destination. The customer may be the carrier himself, for whom the service is need, or an intermediary, such as a forwarder. Customer buys transport performance transportation.

There are other actors in the rail transport services market - in particular infrastructure managers from which railway undertakings buy railway infrastructure capacity and regulatory authorities. Perfect co-operation between individual entities involved in the final product is therefore important because the final customer (transporter) perceives the quality of the shipping process as a whole. In rail transport, this means mainly the coordination of the infrastructure managers 'and carriers' technological processes. (Technological activities and processes of infrastructure manager, railway undertaking, forwarder, the wagons holders, state organs, etc.)

\section{Background and user preferences for created ERIC Mobile application}

\subsection{The background for ERIC Mobile apps}


Schedule of transport is crucial not only to question the place of loading and unloading as well as direction for transportation. The specificity of rail freight traffic is obvious, and road planning has not supported any planning tool available to road hauliers on the Internet. Despite the efforts of the railway companies, it is not easy for the carrier to obtain all the information about the parameters of the transport route. One of the main sources that clearly help in determining traffic parameters is a detailed rail map. (Čamaj, 2018)

As part of this basic task, an electronic railway map of Europe has been developed to provide complete information on a total of 23,000 stations in 40 countries. Likewise, the RailMap platform allows you to instantly provide information and the current location of individual wagons according to carrier requirements. With the growing importance and support of international rail freight, users now have quick access to all relevant information in order to simplify the use of the rail network and can continually ask for the current status of the shipment.(Čamaj - Gašparík, 2011)

The map and the resulting information are a very good basis for displaying additional information, whether transporting the character (current position of trains, wagons and shipments) as well as the technical character of the transport infrastructure (tracks levels, arc radii, transition profiles, etc.).

The map background worked as part of the ERIC platform (European Railway Information Centre). ERIC represents a modular and continuously updated information databank on railway freight transport in the form of an application. The application forms a core with more than 250 individually licensable modules, which provide information about the goods catalogues, railway stations, tariff distances and prices, shipping documents, transport regulations and railway infrastructure. Updated information is provided in electronic form from a processing centre, in various forms and several languages depending on the users' needs.

The fundamental aspect of an electronic information system lies in a well-established centre for data gathering. Information is collected from various sources coming from railway freight in Europe and part of Asia. The original data is processed into a computer format, translated and made accessible to all railway users in the form of single application ERIC. (Camaj - Mašek, 2013) The system is designed for customers and users as the local application for PC equipped with MS Windows.

The ERIC enabled comprehensive information for all users based on the installation and purchased access data. Work with ERIC was therefore bound to a desktop workstation. (Čamaj, 2018)

\section{INFORMATIONS}

In the information section, the customer can find all the information about:

- NHM list of goods - goods nomenclature in 21 languages;
- RID list of dangerous goods - table A and B and connection with the appendix II to SMGS (list of dangerous goods for CIS and Baltic states);

- ETSNG list of goods - list of goods for CIS and Baltic states;

- list of stations and tariff distances (16 carriers);

- information about technical equipment of stations (15 carriers);

- information about track classes LOCA (former regulation RIV II/3);

- information about border stations ENEE (former regulation LIF);

- information about terminals of intermodal transport;

- goods catalogues ETSNG - tariff list of goods for railways of CIS and Baltic states;

- TR6 list of stations - list of stations including comments for railways of CIS and Baltic states;

- freight wagon catalogues of carriers and wagon owners including broad gauge vehicles (20 catalogues);

- a module with a search function according to specified parameters.

The Figure 2 shows the print screen of the basic information about railway wagons.

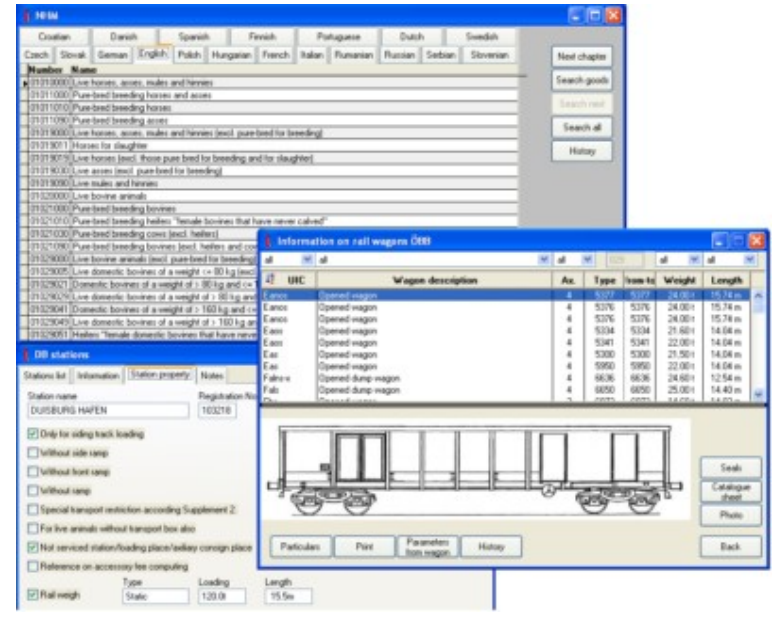

Fig. 2. The basic information about wagons

Source: Čamaj, 2018

\section{INFRASTRUCTURE}

In the section about infrastructure the customer can find the information about>

- database of railway infrastructure parameters for Europe and part of Asia (approx. 50000 track sections);

- information on track sections (track number, length, traction system, number of rails, track class, axle load, gauge, etc.);

- geographic information about the location of approx. 43000 railway stations in Europe and Asia;

- railway network graph of Europe and Asia with a search function for optimal route according to given constraints; 
- calculation of price for usage of rail path for 11 infrastructure owners;

- display of railway infrastructure in RailMap railway map module;

- display of rail corridor in the module of rail map (corridors AGTC, OSZD, TEN-T, RFC);

- calculation of mileage based on railway infrastructure of a specified list of positions of the rail vehicle/traction vehicle.

The Figure 3 present the elementary description of infrastructure in the list view and table view.

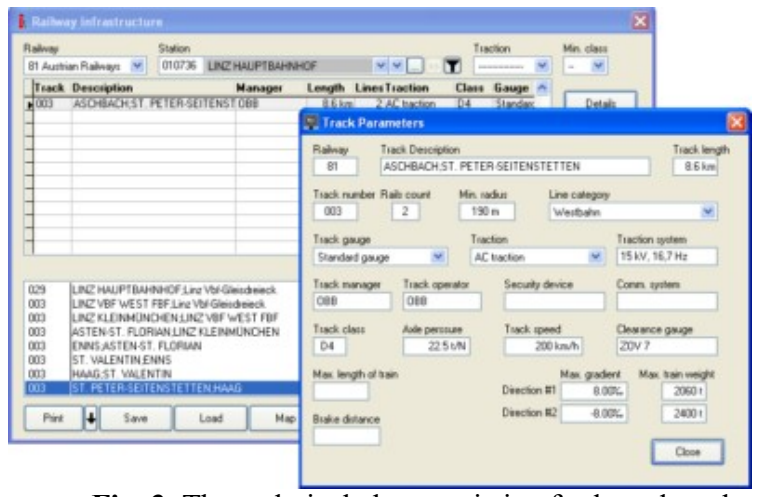

Fig. 3. The technical characteristic of selected track

Source: Čamaj, 2018

\section{THE TRANSPORT PRICE CALCULATION}

The part of the ERIC desktop application can be used for orientation calculation of transport price. For this calculation can be used:

- tariff calculations according to carrier tariffs including additional charges ( 70 basic and union tariffs);

- module for entering and editing of custom price lists;

- price calculation according to custom price lists or carrier tariffs with the option to enter discounts and/or surcharges;

- OPTIM module - search for the cheapest route based on custom and/or tariff price list;

- calculation of transport tariffs including routing according to TP SNG tariff (CIS and Baltic countries);

- tariff distance calculation (distance tables, calculations of export/import/transit distances according to DIUM and TR-4). (See Figure 4.)

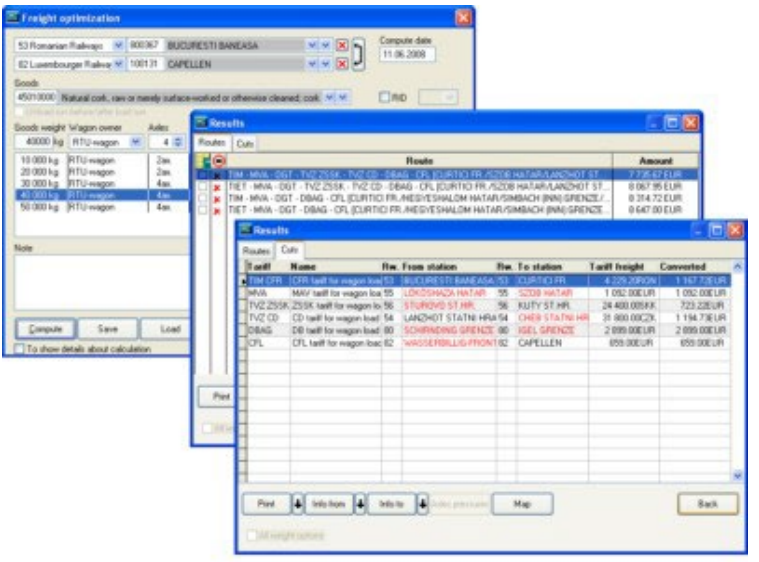

Fig. 4. Calculation of transportation costs Source: Čamaj, 2018

\section{LIBRARY}

For the basic function of the ERIC desktop application are helpful the library of all international and national regulations and standards for railway transportation.

These are:

- national and international tariffs (in the languages of their publication) - text version of tariffs processed into electronic form for simple search;

- guides for filling of consignment notes CIM/CUV, CIM/SMGS;

- regulation for transport of dangerous goods RID in several languages;

- variety of regulations and laws - text version of regulations and laws concerning freight transport.

\section{INTERACTIVE RAILMAP}

For the final planning of the transportation route the user can use the interactive railmap. Specially the user can find and display the information about:

- display of the location of selected railway station;

- display of the location of border stations;

- display of railway infrastructure with indicated traction type and number of rails;

- display of selected rail corridor (AGTC, OSZD, RFC, TEN-T);

- context menu with function for display of nearest railway stations, information on the nearest station, information on the nearest track section;

- user custom tags (insert and edit tags, select tag icon, add a link to the tag);

- option to selectively display/hide layers of the map (roads, rivers, settlements, railways, etc.);

- freightage according to countries in the corresponding currency including VAT (if required);

- option to display transit routes from tariff modules and railway infrastructure module. 

railmap.

The Figure 5 present the printscreen of interactive

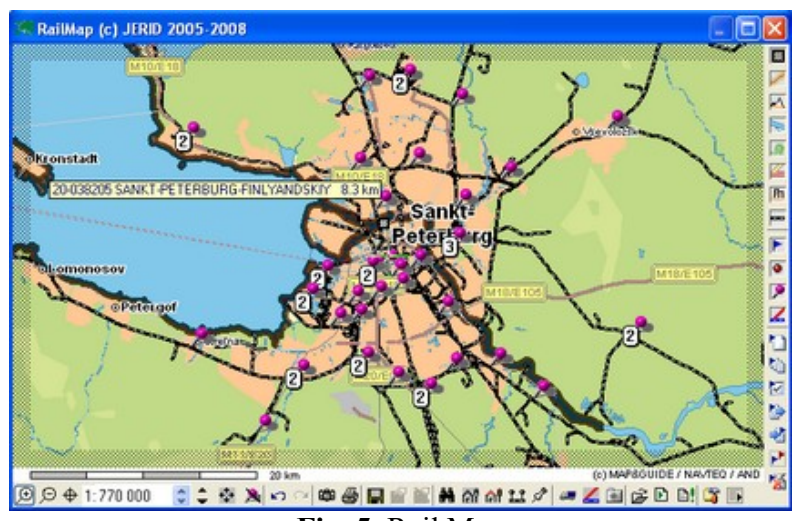

Fig. 5. Rail Map

Source: Čamaj, 2018

\subsection{The user's preferences for ERIC Mobile apps}

Customers' requirements for the developing ERIC Mobile application can be broken down according to the role represented by individual customers in the transport chain.

A large set of application requirements are the same requirements across all customer groups. However, each customer group also has its specific requirements that other groups consider to be marginal.

Common requirements can be included:

- application for all type of mobile operating systems in mobile devices;

- user authentication when signing in to an application (not on installation);

- first download of purchased libraries and application features after logging in;

- application modularity for multiple types of users

- as an off-line application for selected app features (without having to open online libraries on central web-hosting);

- the on-line tracking of shipments;

- the price calculation.

The Railway undertaking requirements to the ERIC Mobile application can be included:

- automated data collection directly into the database (using RFID technology);

- determination of shipment route and calculation of shipping price;

- traffic and transport restrictions on the transport route (temporary and permanent);

- loading and fixation specifications for individual goods.

Among the requirements of forwarders can include:

- the use of multimodal cargo units and the infrastructure to it (terminals, routes);

- calculation of shipping prices;

- load and fixation specifications.

\section{Conclusions}

The map and the resulting information are a very good basis for displaying additional information. It is the transport of the character (current position of trains, wagons and consignments) as well as the technical character of the transport infrastructure (track levels, arc radii, transition profiles, etc.). Under the conditions of rail freight, at each step of the transport chain, one of the trio elements of the train, wagons or shipment is to be identified. And this triad of information gives us comprehensive information on any part of the transport chain.

The major problem of rail freight is the fact that at the outset most of the information on the three elements is entered into the information systems manually and with a time delay. Therefore, the quality of this information is mostly statistic, not the nature of the information for operational management and monitoring.

The importance of the information lies not only in their use in the transport process on the part of the sending railway undertaking. The information also serves to improve and speed up the handling of requirements resulting from the crossing of state borders and to inform all external entities involved in the exchange of information in a timely manner.

The introduction of new approaches to the use of mobile devices for all subjects in the transport market helps to increase the speed and accuracy of the information transmitted and thus partly also helps to increase the competitiveness of rail transport.

\section{Acknowledgment}

The paper was supported by the project EUREKA E!11 156- ERIC Mobile - "European Rail Information Centre in Freight Transport for End-users on Mobile Platforms" at Faculty of Operations and Economics of Transport and Communication, University of Žilina, Slovakia.

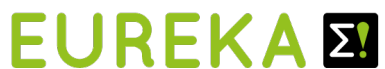

innovation across borders

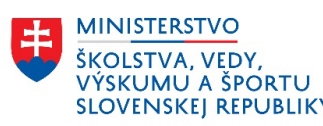

\section{References}

Android (operating system). Available at: https://en.wikipedia.org/wiki/Android_(operating_system)

BlackBerry OS. Available at: https://en.wikipedia.org/wiki/BlackBerry_OS

Čamaj, J. 2018. Information systems to promote efficient management in the field of railway freight transport. Habilitation thesis. 2018. Žilina. 113 pages.

Čamaj, J. - Gašparík, J. 2011. Information and Communications technologies in Railway transport. Žilina: University of Žilina, 2011. 179 pages.

Čamaj, J. - Mašek, J. 2013. Možnosti využitia RFID technológie v dopravných službách. In: Railway transport and Logistic. Vol. 9, No. 2 (2013), Pages 9 - 13. 
Gašparík, J. - Zitrický, V. 2010. Manažment kapacity železničnej infraštruktúry. Žilina: EDIS University of Žilina, 2010. 130 pages.

iPhone OS. Available at: https://en.wikipedia.org/wiki/IOS

Ihnát, P. - Gašparík, J. 2008. Information and telecommunication stechnologies in transport. Interoperability of Railways. Žilina: EDIS University of Žilina, 2008. 163 pages.

Menšík, M. 2018. Smartfóny už využívajú dve tretiny Slovákov, dominuje Andorid. Available at: < https://www.mojandroid.sk/smartfony-vyuzivaju-dvetretiny-slovakov/

Symbian Operating System. Available at: https://en.wikipedia.org/wiki/Symbian

Tengler, J.; Abramović, B.; Achimský, K. 2018. IoT communication in logistics In: Company diagnostics, controlling and logistics: proceedings. - Žilina: Žilinská univerzita, 2018. Pages 251-257.

Tengler, J.; Kolarovszki, P.; Fabuš, J.; Fabušová, V. 2018. Smart services through smart item agent In: SENSORCOMM 2016: the tenth international conference on sensor technologies and applications: Nice, France. Pages 71-76.

Tengler, J.; Kolarovszki, P.; Kolarovszka, Z. 2017. Identification and localization of transport units for selected company In: Procedia Engineering. Vol. 178 (2017), Pages 491-500

Windows Phone (WP). Available at: https://en.wikipedia.org/wiki/Windows_Phone 